\title{
On the track of Artificial Intelligence: Learning with Intelligent Personal Assistants ${ }^{1}$
}

\author{
Nil Goksel-Canbek ${ }^{2}$ \\ Mehmet Emin Mutlu ${ }^{3}$
}

\begin{abstract}
In a technology dominated world, useful and timely information can be accessed quickly via Intelligent Personal Assistants (IPAs). By the use of these assistants built into mobile operating systems, daily electronic tasks of a user can be accomplished 24/7. Such tasks like taking dictation, getting turn-by-turn directions, vocalizing email messages, reminding daily appointments, setting reminders, responding any factual questions and invoking apps can be completed by IPAs such as Apple's Siri, Google Now and Microsoft Cortana. The mentioned assistants programmed within Artificial Intelligence (AI) do create an interaction between human and computer through a natural language used in digital communication. In this regard, the overall purpose of this study is to examine the potential use of IPAs that use advanced cognitive computing technologies and Natural Language Processing (NLP) for learning. To achieve this purpose, the working system of IPAs is reviewed briefly within the scope of AI that has recently become smarter to predict, comprehend and carry out multi-step and complex requests of users.
\end{abstract}

Keywords: Artificial Intelligence, Natural Language Processing, Intelligent Personal Assistants

\section{Introduction}

Technology is a constantly developing and changing aspect of learning. Over the last 30 years of educational revolution, it may be observed that mobile operating systems help users to access information 24/7 through Intelligent Personal Assistants (IPAs) working within Artificial Intelligence (AI). As AI has various application fields and related to computer science and robotics, the term is described broadly by scientists in other disciplines. The first description of the phrase was made by cognitive scientist John McCarthy in the 1950s. According to McCarthy, AI is "the science and engineering of making intelligent machines" (Crevier, 1993, p.50). In addition to that given description, this inspirational, human-like technology has helped computer science to serve software systems working with intelligent behavior.

\footnotetext{
${ }^{1}$ This article is a revised version of the paper presented in the 1 st International Conference on Lifelong Education and Leadership for ALL (ICLEL 2015), October 29-31, The Czech Republic.

2 Ph.D.c, School of Foreign Languages, Anadolu University. ngoksel@anadolu.edu.tr

${ }^{3}$ Ph.D., Open Education Faculty, Anadolu University. mmutlu@anadolu.edu.tr
} 
Goksel-Canbek, N., \& Mutlu, M. E. (2016). On the track of Artificial Intelligence: Learning with Intelligent Personal Assistants. International Journal of Human Sciences, 13(1), 592-601. doi:10.14687/ijhs.v13i1.3549

The term of AI, also defined as "Machine Intelligence" or "Computational Intelligence", encompasses a buge variety of subfields, ranging from general-purpose areas, such as learning and perception to such specific tasks as playing chess, proving mathematical theorems, writing poetry, and diagnosing diseases (Russell \& Norvig 2003, P.1). As connoted by Ray Kurzweil (2014), AI can be regarded as a pivotal technology today which is advanced in many fields such as health (to diagnose diseases and help the disabled), clean energy (to develop renewable clean energy) and high-quality education. In this connection, it can be observed that the field of AI, in relation with other areas of science and education, is currently creeping into daily lives of users via various devices of PDAs and their new forms of mobile applications as IPAs. In this regard, the overall purpose of this study is to review the PDA systems using Natural Language Processing (NLP) and examine IPAs (Apple's Siri, Google Now and Microsoft Cortana) in detail as the part of a world's well-known mobile operating systems that could be used in future's education.

\section{Artificial Intelligence at a Glance}

Being used in many areas such as computer science, cognitive and learning sciences, game design, psychology, sociology, philosophy, mathematics, neuroscience, linguistics, defense industry, medicine and education. Artificial Intelligence (AI) has lately been propelled into the mainstream of learning. Aiming to use the techniques of search and pattern matching for providing solutions for the demanded answers, AI uses logical series of steps called algorithms and advanced cognitive computing technologies. AI, as an interdisciplinary field, is used for diagnosis of illnesses, criminal identification and artificial instructions and has different scope of data in terms of the developments in the above-mentioned fields as it includes the ability to reason while processing a natural language to develop communication between human and computer (Vernor, 2015). Similar to modern day, in the past, AI was still an aspiration rather than an achievement and should be applied with considerable caution in real learning situations (Last, 1990, p.243; Schwind, 1990). Table 1 summarizes some of the primary definitions made and categorized between 1978 and 1998 (Russell \& Norvig, 2010, p.2):

\begin{tabular}{|c|c|}
\hline Systems that think like humans & Systems that think rationally \\
\hline $\begin{array}{l}\text { "The exciting new effort to make computers } \\
\text { think ... machines with minds, in the full and } \\
\text { literal sense." (Haugeland, 1985) } \\
\text { "[The automation of] activities that we } \\
\text { associate with human thinking, activities such } \\
\text { as decision-making, problem solving, } \\
\text { learning..." (Bellman, 1978) }\end{array}$ & $\begin{array}{l}\text { "The study of mental faculties through the } \\
\text { use of computational models." } \\
\text { (Chamiak and McDermott, 1985) } \\
\text { "The study of the computations that make it } \\
\text { possible to perceive, reason, and act." } \\
\text { (Winston, 1992) }\end{array}$ \\
\hline Systems that act like humans & Systems that act rationally \\
\hline $\begin{array}{l}\text { "The art of creating machines that perform } \\
\text { functions that require intelligence when } \\
\text { performed by people." (Kurzweil,1990) } \\
\text { "The study of how to make computers do } \\
\text { things at which, at the moment, people are } \\
\text { better." (Rich and Knight, 1991) }\end{array}$ & $\begin{array}{l}\text { "Computational Intelligence is the study of } \\
\text { the design of intelligent agents." (Poole et al., } \\
\text { 1998) } \\
\text { "AI ...is concerned with intelligent behavior } \\
\text { in artifacts." (Nilsson, 1998) }\end{array}$ \\
\hline
\end{tabular}


As a striking innovation that pushing new boundaries, AI, has some other descriptions as well. According to Nabiyev (2005), the term signifies range of abilities of a computer system to comprehend, learn, solve, interpret and execute complex mental process. Based on these descriptions, it may be stated that $\mathrm{AI}$ is an umbrella term for handheld mobile devices (originally PDAs) and mobile applications (IPAs) has recently become smarter to predict, comprehend and carry out multi-step and complex requests of users.

\section{Natural Language Processing (NLP)}

Artificial Intelligence (AI) as a subfield of computer science and human computer interaction may be provided via Natural Language Processing (NLP) in order to combine human learning and machine reasoning. As expressed by Verspoor and Cohen (2013, p.1495), NLP is the analysis of linguistic data, most commonly in the form of textual data such as documents or publications, using computational methods. To the researchers, the main aim of the process is to build a representation of a text by including structural addings and insights from linguistics. NLP seems to be the most crucial element for creating computer software that provides the human-computer interaction for storing initial information, solving specific problems, and doing repetitive tasks demanded by the user. Nabiyev $(2005,475)$ collates the functions of the natural language analysis as below:

to verify the sentences used in natural language

$>$ to correct the spelling errors

$>$ to form a syntactic structure of the sentences

$>$ to provide semantic relation

to combine syntactic structure of the sentences and semantic relation for appropriate responding

By using NLP, demanded questions on a specific topic or subject consisting of sentences, phrases and words can be computerized appropriately and be responded via PDAs and IPAs programmed within the scope of AI.

\section{Personal Digital Assistants (PDAs)}

With the most recent attempts taken in computer science, information can be reached and released in seconds today. Designed within the frame of Natural Language Processing and AI, the search engines become able to find and bring information from big data stack easily (Kayabaş, 2010). In parallel technological developments within the computer science, devices have evolved in time. PDAs, also known as handheld PCs or personal data assistants (Viken, 2009), were first released in the middle of 1980s in order to ease the users' daily lives and enable the mentioned data access. Likewise search engines, diverse types of PDAs were regarded as crucial handheld devices that have been used by multiple disciplines since their introduction in the mid-1990s (Ranson, Boothby, Mazmanian, Alvanzo, 2007). In the following steps of these developments, PDAs started to be used for daily scheduling, set up appointments as portable devices designed with touch screen technology that frees the user to record telephone numbers, addresses, appointments and to-do lists (Lenox, Terri, Woratschek \& Charles, 2002). However, PDAs have eventually become obsolete due to rapid technological changes in the world of mobile devices (Beal, 2015). Based upon this alteration, PDAs today may be considered as ancestry devices of recent mobile innovations including smart phones and tablets. 
Goksel-Canbek, N., \& Mutlu, M. E. (2016). On the track of Artificial Intelligence: Learning with Intelligent Personal Assistants. International Journal of Human Sciences, 13(1), 592-601. doi:10.14687/ijhs.v13i1.3549

\section{Intelligent Personal Assistants (IPAs)}

With close ties to the above mentioned parts described, Intelligent Personal Assistants (IPAs) are speech-enabled technologies in mobile platforms which have become one of the fundamental devices of learning online. As illustrated by Hauswald et al. (2015, p.223), an IPA is an application that uses inputs such as the user's voice, vision (images), and contextual information to provide assistance by answering questions in natural language, making recommendations, and performing actions. The widespread applications of IPAs are designed to perform the required tasks of the users via using online sources available on the Internet. As connoted by Garrido et al. (2010, p.3) the most common application has been filtering information in the Web through software agents specialized in tasks such as improving the information retrieval process, or supporting users through recommender systems. IPAs, on the other hand, are personalized applications on which users may have preferences over a wide range of functions within the system, including how tasks are performed, how and when meetings are scheduled, and how the system interacts with the user (Myers et al., 2007). Combining advanced technologies with AI, IPAs namely Amazon Echo, BlackBerry's 'BlackBerry Assistant', Braina, Google's 'Google Now', HTC's 'Hidi', Maluuba Inc's 'Maluuba', Microsoft's 'Cortana', Motorola's Mya (unreleased), Samsung's 'S Voice', Cognitive Code's 'SILVIA', Apple's 'Siri', Nuance's 'Vlingo', LG's 'Voice Mate', IBM's 'Watson', Facebook's 'M (Moneypenny)' and applications like Dragon, Indigo, Skyvi, Voice Actions, Voice Search, EVA Intern, Iris, IBM Watson, Maluuba, Evi, Jeannie, Speaktoit, AIVC and Wolfram Alpha, Dahi, Duolingo, Ata, Jeannie, Andy X, ACO or Assistant B, Anki, Memrise, Pimsleur and Livemocha etc. may help learning online. Among these enumerated software agents, some already perform basic tasks of the user commands including chitchatting, text messaging, emailing, alarm setting and some for second language learning.

As posted by Matney (2015), Apple, Google, Microsoft, Amazon and Facebook have been five robust tech titans that provide their own IPAs such as Siri, Now, Cortana, Alexa and $M$ with which instant communication and interaction have been provided through AI in recent years. As stated by Stephen Hawking (2014), an English theoretical physicist, cosmologist, author, Siri, Google Now and Cortana are the unprecedented investments and greatest products of human intelligence created in human history. Despite its cons, their potential usage for learning might still worth searching. In this study, the most commonly well-known tech giants which have their own voice assistant like Siri, Now, Cortana will be analyzed in general.

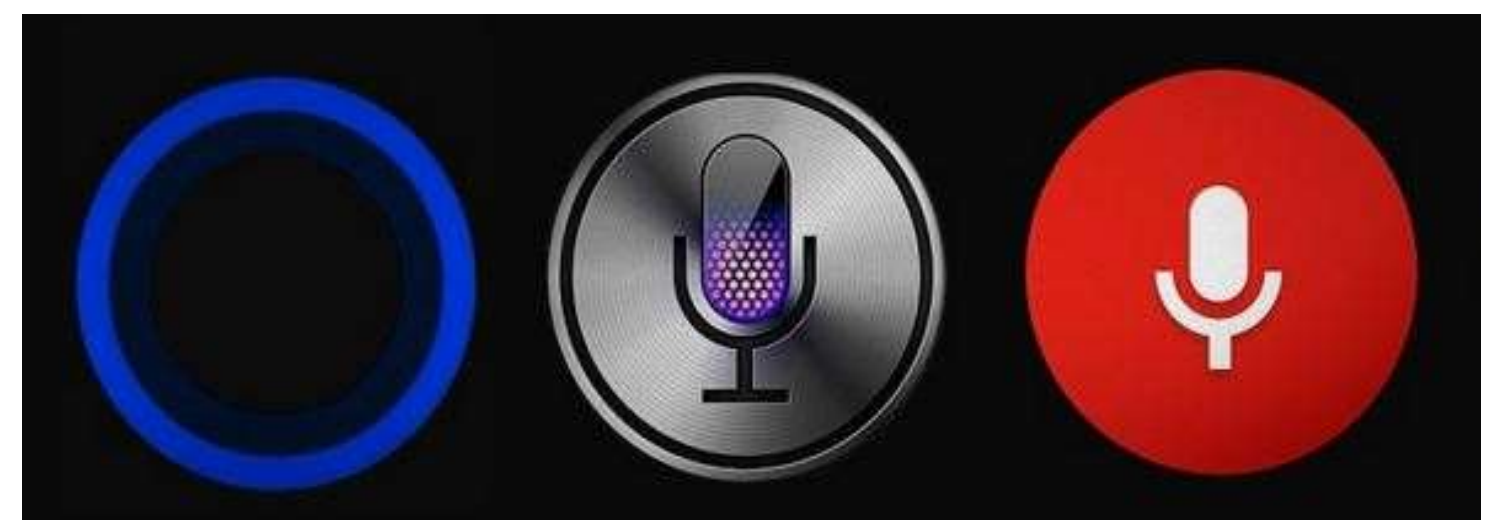

From left to right: Cortana, Siri, Google Now

(Litchfield, 2015) 


\section{Learning with PDAs and IPAs}

Developed on a spoken dialogue system that uses a natural spoken language and semantic understanding techniques in an attempt to help the users obtain desired information (Chen, 2015), IPAs could be used for self-learning purposes. As also indicated in Horizon Report by Johnson, Becker, Estrada and Freeman (2014), the virtual assistants encourage convenience and productivity, making them particularly compelling for their potential applications in academic settings, though they are four to five years away from being widely used in higher education (p. 46). IPAs in this regard could be estimated as devices to improve listening and speaking skills of the learners. As underlined by Miangah and Nezarat (2012), embedded pronunciation activities in mobile devices such as PDAs could be used through downloadable online dictionaries with sound functions in order to teach correct phonetic form of words. To the same researchers, the speech aspect of mobile learning is as significant as textual aspect of $i t$, since it enables learners to comfortably speak with a system recording their voice and allowing them to listen back to themselves (p. 314). In this connection, the speech/language enabled IPAs may enhance learners' listening and speaking skills without being bound up with native-speaker humans. As pointed out by Markowitz (2013), the smart assistants, as devices perform at human levels with facial expressions, linguistic prowess, and cognition, IPAs can assist the learners for language learning with no constraints of time and space.

\subsection{Apple's Siri}

As an operating system of iOS, Siri is one of the salient application of Apple that caught the close attention of the tech-savvy public. The origin of the Siri innovation can be traced back to 2003 when CALO (Cognitive Assistant that Learns and Organizes), the artificial intelligence project was funded by the Defense Advanced Research Projects Agency (DARPA).

In 2003, DARPA entered into an agreement with SRI International which later incorporated a separate entity, Siri, Inc. in 2007 and finally was released as a virtual personal assistant application for the iPhone in February 2010 (Markoff, 2008). Running on the iPhone (4S and later), iPod touch (fifth generation and later), iPad touch (third generation and later), iPad Air and all versions of the iPad mini (Sadun \& Steve, 2014).

After being introduced to the world in October 2011, American public's mostly accustomed talking devices, like automated customer service phone representatives, elevators or car global positioning systems, were all replaced with Siri that was hoped to simplify people's lives (Goss, 2015) in a technological sense. Even though it uses multiple search engines such as Google, Yahoo and Yelp, Siri is not considered as a search engine.

An iPad expert Daniel Nations (2015) describes Siri as a voice recognition artificial intelligence decision engine which can remind an event at a specific date or time, schedule/change an appointment, get involved in social media (tweet or update Facebook status) in reference to user's commands. What makes Siri interesting is its AI supported design structured on natural voice to carry out the given tasks with a 'sense of humour'. With an attempt to make Siri seem more human like character, optional female or male voices become involved in user's lives to answer questions. Programmed with various databases, Siri can answer the sample questions as given below:

> What is 18 "percent" of 32 "dollars" 57 "cents"?

$>$ How much is 20 British pounds in dollars?

$>$ Where is Palacky University Education Faculty?

Dhen is mother's day in 2016? 
Goksel-Canbek, N., \& Mutlu, M. E. (2016). On the track of Artificial Intelligence: Learning with Intelligent Personal Assistants. International Journal of Human Sciences, 13(1), 592-601. doi:10.14687/ijhs.v13i1.3549

Apart from answering the question samples below, Siri's way of communicating to the user can be found not "siri" ous as indicated by the blog writer Errol Jayawardene (2015). However, these conversations might help users to be involved in ESL (English as a Second Language) and EFL (English as a Foreign Language) activities in terms of improving language skills specifically on speaking (pronunciation) and listening. Some of the dialogue examples of Siri are as below (Jayawardene, 2015):

\section{User: What's up?}

Siri: I was just gazing out of my window trying to pen some baikus.

Siri: I'm checking my heart rate on Apple Watch. If I only had a heart.

User: What does Siri mean?

Siri: I don't think I can explain it in your language. Sorry.

User: Did you know Steve Jobs?

Siri: Thanks for asking about Steve. Here's Apple's webpage about him.

\section{User: What is the meaning of life?}

Siri: Try to be nice to people, avoid eating fat, read a good book every now and then, get some walking in and try to live together in peace and harmony with people of all creeds and nations.

\section{User: Why do we exist?}

Siri: Well, that chocolate isn't going to eat itself.

User: Are you sure?

Siri: Well, I enjoy a good equivocal statement now and then.

User: What came first, the chicken or the egg?

Siri: It seems that human civilization has been anfully preoccupied with this question.

User: Do you dance?

Siri: I do a pretty mean robot.

\subsection{Google Now}

With a similar voice and language recognition based feature of the other IPAs, Google Now as a voice-activated assistant, investigates the questions asked, and marks the dates or events crucial for the users. Unlike Siri, Google Now is a search engine which is designed to listen and comprehend the commands and queries of the users. Running on a Samsung, Galaxy with its Android versions, the engine, automatically opens up the most relevant webpage when searched via voice commands, eliminating the need to specify a website URL (Vaidya, Zhang, Sherr \& Shields, 2015).

What makes Google Now unique is its rare feature of using AI more actively. Once the users visit a site, the application notes the interests and preferences of the users automatically. Supporting this feature, the application as an active user of AI, gathers data from user accounts and combine sensor data from mobile phones in order to provide suggestions (Gottipati et al., 2014). To the the writers, the best time to travel, for instance, can be advised by the engine through its combined data received from the information previously given by the user like the location of the user's next appointment along with the time, traffic data, current location and Google Calendar. Hence, the engine pre-empts the users' demands and provides information by using a natural language and is able to predict what information a user needs based on the previous searches and context data. (Dobre \& Xhafab, 2013). Below are some of the sample questions that could be asked to Google Now: https://support.google.com/websearch/answer/2940021?hl=en:

\footnotetext{
Where was Albert Einstein born?

$>$ What's the square root of 2209?

$>$ Show me pictures of the Golden Gate Bridge.
} 
With its voice and language recognition based features, Google Now could also be used as an IPA to learn a second language with correct pronunciation form. Differently from Apple's Siri, users do not have to talk into the typical robot like pattern to give commands to the device because the engine understands the meaning the user commands and queries more accurately (Kale, 2012).

\subsection{Microsoft Cortana}

Named of an AI character in the Halo Video Game series, like Siri and Google Now, Cortana helps the users to make calls, send messages, set reminders, take notes, recognize music, find great restaurants nearby, check your calendar and more (Tariq, 2014). Created by Microsoft for Windows Phone 8.1 and powered by the search engine: Bing, Cortana was officially unveiled at the Microsoft BUILD Developer Conference held between April 2 and April 4 in 2014 (Chris, 2014). Sharing the similar features of Apple's Siri and Google Now, Cortana is getting better at answering user queries for more and more scenarios every day, from adding reminders for obtaining directions, tracking flights, and many more (Elwany \& Shakeri, 2014, p.1 ). Below are some of the ideas referring "Cortana-user" interaction given by Windows Phone 8 official web site http://www.windowsphone.com/en-us/howto/wp8/cortana/what-can-i-say-to-cortana:

$\begin{aligned} & >\text { How much protein in a cup of milk? } \\ \text { General Questions } & >\text { Convert } 60 \text { dollars to yen } \\ & >\text { Find a cheap pizza place that's open now } \\ & >\text { Get me directions to the Grand Canyon } \\ & >\text { Where am I? } \\ & >\text { How long will it take me to get to the Space Needle? } \\ & >\text { Show me a map of } 123 \text { Main Street } \\ & >\text { How far to Four Corners National Park? } \\ \text { Maps and directions } & >\text { What's traffic like on the way to work? }\end{aligned}$

Likewise Google Now, Cortana saves the previous information consisting of location data, behaviors, personal information, reminders, and contact information in a Notebook system (Warren, 2014). Having these similar corresponding features, educational use of Cortana seems to be promising. According to Ray Fleming (2014), Cortana would be a splendid assistant for timepoor or disorganized students. Here are some of the examples given in an education dimension:

When/what/where is my next lesson?

$>$ When is my next science lesson?

$>$ When is my next essay due?

$>$ Remind me to talk about the Ice Age next time I meet Year 7 Geography.

Below is the table showing the comparison of the three dialogue systems (Howes and Larsson, 2015):

\begin{tabular}{|l|l|l|l|}
\hline \multicolumn{7}{|l|}{ Table 2. Comparison of Google Now-Siri-Cortana } \\
\hline & Google Now & Siri & Cortana \\
\hline Over-answering & misunderstood & + & + \\
Other-answering & misunderstood & + & ignored \\
Embedded revision & ignored & halts & halts \\
\hline
\end{tabular}


As it can be observed from Table 2, Google Now, being compared to the other dialogue systems, seems less functional in contrast with the explanations given in the above parts of this study. As explained in detail by Howes and Larsson (2015), Google Now is not intended as a full dialogue system. Cortana, likewise Google Now also failed in performance. Siri on the other hand, did quite well; however, all these three systems need to be regularly viewed to get a continuous progress. The same exploration may also be done for second language learning via these systems.

\section{Conclusion}

The paths of this study regarding IPAs is intended to reveal an overview on how and to what extent these devices might be used in human-computer interaction and learning. In this connection, the working systems of the IPAs namely Apple's Siri, Google Now and Microsoft Cortana are revised within the context of AI. Although there have been several works related to IPAs in education (also known and conceived as Intelligent Pedagogical Agents by Garrido et al. (2010, p.4) the potential use of IPAs for second language learning within Natural Language Processing (NLP) should be focused particularly. In this regard, it may be suggested that both devices (PDAs) and applications (IPAs) might be used as feasible tools for language learning; so more qualitative and quantitative studies may be conducted accordingly.

\section{References}

Beal, V. (2015). PDA - personal digital assistant. Webopedia Online Dictionary. Retrieved from http://www.webopedia.com/TERM/P/PDA.html

Chen, Y. N. V. (2015). Learning Organized Knowledge for Unsupervised Spoken Language Understanding. Unpublished doctoral dissertation, Carnegie Mellon University, Pennsylvania, USA. Retrieved from http://www.cs.cmu.edu/ yvchen/doc/dissertation.pdf

Chris, L. (2014). Why Cortana Assistant Can Help Microsoft in the Smartphone Market. The Street. Retrieved from http://www.thestreet.com/story/12534433/1/why-cortana-assistant-canhelp-microsoft-in-the-smartphone-market.html

Crevier, D. (1993). AI: The Tumultuous Search for Artificial Intelligence. New York, NY: Basic Books, ISBN 0-465-02997-3

Dobre, C., \& Xhafab, F. (2013). Intelligent services for Big Data science. Future Generation Computer Systems, 37(2014), 267-281.

Elwany, E., \& Shakeri, S. (2014). Enhancing Cortana User Experience Using Machine Learning. Recall, 55(54.61), 24-24.

Fleming, R. (2014). Could Cortana in education help students and teachers? Microsoft Education Blog. Retrieved from http://blogs.msdn.com/b/education/archive/2014/09/08/could-cortanain-education-help-students-and-teachers.aspx

Garrido, P. \& Martinez, F. J. and Guetl, C. (2010). Adding Semantic Web Knowledge to Intelligent Personal Assistant Agents, In Cudre-Mauroux, P. and Parsia, B. (ed), ISWC 2010 - The Ninth International Semantic Web Conference, Nov 7 2010, 1-12. Shanghai, China.

Goss, E. A. (2015). The Artificially Intelligent Woman: Talking Down to the Female Machine, Columbia University Academic Commons, Retrieved from http://academiccommons.columbia.edu/catalog/ac:186107 
Goksel-Canbek, N., \& Mutlu, M. E. (2016). On the track of Artificial Intelligence: Learning with Intelligent Personal Assistants. International Journal of Human Sciences, 13(1), 592-601. doi:10.14687/ijhs.v13i1.3549

Gottipati, S., Sebastian, J., Tuan, L. T., Wee, T. K., Chan, J., Keng, J. Muralidharan, K., Okoshi T., Leel, Y., Misra A. \& Balan, R. K. (2014). Mobile platform and application research at SMU LiveLabs. In Communication Systems and Networks (COMSNETS), 2014 Sixth International Conference on IEEE. 1-4. Retrieved from http://ieeexplore.ieee.org/xpls/abs all.jsp?arnumber=6734911

Hauswald, J., Laurenzano, M. A., Zhang, Y., Li, C., Rovinski, A., Khurana, A., Dreslinski, R. G., Mudge, T., Petrucci, V., Tang, L. \& Mars, J. (2015). Sirius: An open end-to-end voice and vision personal assistant and its implications for future warehouse scale computers. In Proceedings of the Twentieth International Conference on Architectural Support for Programming Languages and Operating Systems. p.223-238. ACM.

Hawking, S., Russell, S., Tegmark, M., \& Wilczek, F. (2014). Stephen H awking: Transcendence looks at the implications of artificial intelligence-but are we taking AI seriously enough? The Independent, 2014(05-01)

Jayawardene, E. (2015). A not so Siri-ous conversation [Blog post]. Retrieved 15 from http://www.rlyl.com/siri-ous-conversation/

Johnson, L., Becker, S., Estrada, V., \& Freeman, A. (2014). Horizon Report: 2014 Higher Education. Retrieved from http://www.editlib.org/p/130341/

Kale, S. (2012). Apple's New iPad And Asus Transformer Prime-Comparison. TricksWindow. Retrieved from http://www.trickswindow.com/google/google-now-apple-siricomparison/

Kayabaş, İ. (2010). Usability of artificial intelligent conversational agents as student support service in distance education. Unpublished MA Thesis. Social Science Graduate Institute, Anadolu University, Eskisehir.

Kurzweil, R. (December 19, 2014). Don't Fear Artificial Intelligence. Time,

Retrieved from http://time.com/3641921/dont-fear-artificialintelligence/

Larsson, S. (2015). The State of the Art in Dealing with User Answers. In Proceedings of the 19th Workshop on the Semantics and Pragmatics of Dialogue. SEMDIAL 2015 goDIAL. 190-191.

Lenox, Terri L., Woratschek, Charles, R. (2002). Personal Digital Assistants. Computer Sciences. Retrieved from http://www.encyclopedia.com/doc/1G2-3401200254.html

Litchfield, S. (2015). Cortana vs Siri vs Google Now vs Blackberry Assistant - fight! AAWP - All About windows Phone. Retrieved from http://allaboutwindowsphone.com/features/item/20697 Cortana vs Siri_vs Google No w-.php

Matney, L. (2015). A Battle Royale Of Digital Assistants: The Big 5. TechCrunch.

Retrieved from http://techcrunch.com/gallery/a-battle-royale-of-digital-assistants-the-big-5/

Markoff, J. (2008). A software secretary that takes charge. New York Times, 13, 12. Retrieved from http://www.mondaq.com/unitedstates/x/176106/Telecommunications+Mobile+Cable+ Communications/SIRI $+\mathrm{Is}+\mathrm{My}+\mathrm{Client}+\mathrm{A}+$ First + Look + At + Artificial + Intelligence + And +Legal+Issues

Markowitz, J. A. (2013). Beyond SIRI: Exploring Spoken Language in Warehouse Operations, Offender Monitoring and Robotics. In Mobile Speech and Advanced Natural Language Solutions. 3-21. Springer New York. 
Goksel-Canbek, N., \& Mutlu, M. E. (2016). On the track of Artificial Intelligence: Learning with Intelligent Personal Assistants. International Journal of Human Sciences, 13(1), 592-601. doi:10.14687/ijhs.v13i1.3549

Miangah, T. M., \& Nezarat, A. (2012). Mobile-Assisted Language Learning. International Journal of Distributed and Parallel Systems, 3(1), 309-319.

Myers, K., Berry, P., Blythe, J., Conley, K., Gervasio, M., McGuinness, D. Morley, D., Avi Pfeffer, A., Pollack, M. \& Tambe, M. (2007). An intelligent personal assistant for task and time management. AI Magazine, 28(2), 47-61.

Nabiyev V. V. (2005). Yapay Zeka; Problemler-Yöntemler-Algoritma, Ankara: Seçkin Yayıncılık.

Nations, D. (2015). What is Siri? A Look at Apple's Personal Assistant for iOS. About.com, Retrieved from http://ipad.about.com/od/iPad-FAQ/a/What-Is-Siri.htm

Ranson, S. L., Boothby, J., Mazmanian, P. E., \& Alvanzo, A. (2007). Use of personal digital assistants (PDAs) in reflection on learning and practice. Journal of Continuing Education in the Health Professions, 27(4), 227-233.

Russell, S., \& Norvig, P. (2003). Artificial intelligence: A modern approach (2nd ed.). Pearson Education, Inc., Upper Saddle River, New Jersey

Sadun, E., \& Sande, S. (2014). Talking to Siri: Mastering the Language of Apple's Intelligent Assistant. Que Publishing.

Schwind, C. (1990). Review of Artificial intelligence techniques in language learning by Rex W. Last. Ellis Horwood 1989. Computational Linguistics, 16(4), 242-244.

Tariq, K. (2014). Siri, Google Now, Cortana: The Ultimate Digital Voice Assistant? WCCFTech.com, Retrieved from http://wccftech.com/digital-voice-assistant/\#ixzz3lcDQvCrq

Vaidya, T., Zhang, Y., Sherr, M., \& Shields, C. (2015, August). Cocaine noodles: exploiting the gap between human and machine speech recognition. In Proceedings of the 9th USENIX Conference on Offensive Technologies. 1-14. USENIX Association. Retrieved from https://www.usenix.org/system/files/conference/woot15/woot15-paper-vaidya.pdf

Vernor, V. (2015). What is Artificial Intelligence? Retrieved from Singularity Institute Africa Website: http://www.singularityinstituteafrica.com/what-is-artificial-intelligence.html

Verspoor, K., \& Cohen, K. B. (2013). Natural language processing. In Encyclopedia of Systems Biology (pp. 1495-1498). Springer New York.

Viken, A. (2009). The history of personal digital assistants 1980-2000. Agile Mobility. http://agilemobility.net/2009/04/thehistory-of-personal-digital-assistants1.

Warren, T. (March 3, 2014). This is Cortana, Microsoft's answer to Siri. The Verge. Retrieved from http://www.theverge.com/2014/3/3/5465264/microsoft-cortana-windows-phone$\underline{\text { screenshots }}$ 